\title{
Educación y Construcción de COMUNidAD: ESTUdio de CASO SOBRE EL SENTIDO QUE DAN A LA EDUCACIÓN ESTUDIANTES ADULTOS Y EDUCADORES PARTICIPANTES DE UN PROYECTO EDUCATIVO comunitario, en Villa Valle Verde, Maipú.
}

\author{
Education and Community Building: Case study about
} THE MEANING GIVEN TO EDUCATION BOTH ADULTS STUDENTS AND TEACHERS IN A COMMUNITY EDUCATIONAL PROJECT, FROM VILLA Valle Verde, Maipú.

\author{
Daniela Gacitúa Solorza \\ Especialista en Currículum y Comunidad Educativa \\ Profesional de la Coordinación Nacional de EPJA, MINEDUC. \\ Teatinos 20, piso 9, oficina 93. \\ danielagacitua@gmail.com
}

Resumen: Esta investigación cualitativa recoge la experiencia de los pobladores de Valle Verde, quienes desarrollan un Proyecto Educativo autogestionado. Situando el problema en el contexto de la desigualdad económica en Chile, en una relación especular con la desigualdad educativa, traducida en una educación para pobres y otra para ricos, trazó el camino para pensar la vinculación entre la educación de los pobres y la educación de adultos.

Con objeto de conocer el sentido que tiene la educación para la comunidad y sus representaciones respecto del sistema educativo, utilicé la teoría fundamentada y un enfoque hermenéutico-interpretativo, destacando como hallazgo principal la emergencia de un nuevo vínculo entre los participantes del Proyecto, conceptualizado como el lazo vecinos-compañeros, relevando el sentido comunitario de su práctica.

Palabras clave: educación de adultos, comunidad, autoeducación, vecinoscompañeros.

Abstract: This qualitative research reflects the experience of Valle Verde people, who develop a self-managed Educational Project. Placing the problem in a context of economic inequality in Chile, in a specular relationship with the educational inequity, which can be translated into a divided education: one for the poor and another one for the rich, making way for thinking about the link between poor education people and adult education.

In order to know the meaning of education for the community and their representations about the educational system, I used the grounded theory an hermeneutical interpretive approach, highlighting as main finding, the emergence of a new link between the project participants, conceptualized as tie neighbours-mates, relieving the sense of community practice.

Keywords: adult education, community, self-education, neighbours-mates. 


\section{INTRODUCCIÓN}

Nuestra imagen internacional, dentro de los países que integran la OECD, nos proyecta como una de las naciones con mayor desigualdad, donde los ingresos del 10\% más rico en Chile son 26 veces más altos que los del 10\% más pobre (OECD, 2015: 1). Ha habido avances en la reducción de la pobreza a partir del 2000, sin embargo, estamos por debajo del promedio de los países que integran este organismo, con una pobreza relativa del 18\% comparada con la media de la OECD del 11,5\%. En correlato con estos datos, como una de nuestras tantas heridas, nuestro sistema educativo exhibe las brechas de la desigualdad, problema sobre el que se juega el conflicto entre concepciones de educación incluso antagónicas y en función de las cuales se decide cómo actuar para avanzar en esta materia. Así observamos las tensiones entre posiciones que defienden la educación como un bien de consumo frente a las que la defienden como un derecho.

Sin embargo, la educación de nuestro país y, por tanto, las desigualdades que la caracterizan, se ve determinada no sólo por condicionantes económicos, sino también por las configuraciones socioculturales que se vienen gestando en Chile desde los inicios de la República. Siguiendo esta doble línea problemática, constatamos en la sociedad chilena el cruce de dos tipos de valores e ideales surgidos en contextos históricos distintos, pero que dan cuenta, en su actual aleación, del tipo de educación que tenemos y de su profunda crisis. De una parte, y en un contexto histórico más reciente, los ideales y valores que vinieron de la mano con la implantación de una sociedad de mercado, centrados principalmente en la libertad, el individualismo y el progreso. De otra, dirigiendo la mirada hacia nuestra historia pretérita, los ideales de sociedad y de nación que fueron forjados, principalmente, por uno de los intelectuales ilustrados que participó activamente en la construcción del Estado Nacional en Chile, el venezolano Andrés Bello, quien en sus varios años de estadía y colaboración en nuestro país, impregnó nuestra cultura con anhelos de orden, estabilidad y consenso.

\section{EL ELITISMO DE LA EDUCACIÓN CHILENA}

El carácter elitista de la educación chilena debe mucho al Proyecto Educativo de Bello, que recogía los ideales republicanos emanados desde Europa, pero reproduciendo la segregación en Hispanoamérica: democracia, pero representativa; educación para todos, pero no la misma. Tal como señala García de la Huerta (2013), el ideal ilustrado de universalidad aparece sesgado 
en su propia representación de sociedad ideal y en su implementación en los inicios de Chile independiente. Idea que se reafirma si consideramos que Bello creía que:

No todos los hombres han de tener igual educación, aunque es preciso que todos tengan alguna, porque cada uno tiene distinto modo de contribuir a la felicidad común. Cualquiera que sea la igualdad que establezcan las instituciones políticas, hay sin embargo en todos los pueblos una desigualdad, no diremos jerárquica (que nunca puede existir entre republicanos, sobre todo en la participación de los derechos públicos) pero una desigualdad de condición, una desigualdad de necesidades, una desigualdad de método de vida. A estas diferencias es preciso que se amolde la educación para el logro de los interesantes fines a que se aplica (Citado en Zemelman \& Jara, 2006, p. 20).

El proyecto educativo de Bello se desarrolló en correlación con el modelo sociopolítico oligárquico, basado en un sistema de dominación de los criollos, quienes concentraban la mayor parte de los bienes y constituían un grupo reducido frente a la mayoría de la población que era campesina en ese entonces. De hecho, el rol de los pueblos en la construcción del Estado nacional chileno fue [...] decreciente. Y en definitiva, a medida que se fueron desarrollando la clase política y los partidos, ese rol fue anulado" (Salazar, Mancilla \& Durán, 1999, p. 271). La noción esencialista de Bello, de una desigualdad de condición lo impulsa a reducir el imaginario social a dos polos y, en este sentido, el esquema dual de la educación propuesto por Bello, de una educación para ricos y otra para los pobres, se adaptaba a la organización social de la época, cumpliendo un fin disciplinador y estructurador de la sociedad, considerando que el interés principal de este intelectual ilustrado consistía en pensar cómo se construye una sociedad en el contexto de independencia nacional.

\section{LA EDUCACIÓN DE LOS POBRES Y LA EDUCACIÓN DE ADULTOS}

Cuando surge la educación de adultos en el siglo XVIII, luego de la Revolución Industrial en Inglaterra, sus fines respondían a la necesidad de la época de formar a la masa trabajadora y de hacer una mano de obra calificada. Ciencia e industria se convierte en el principio que rige el surgimiento histórico de la educación popular y que le da una impronta a la educación de adultos.

Si bien Tiana (1991) advierte que no hay mucha literatura respecto a los antecedentes de la educación de adultos durante el siglo XVIII, destaca que 
en este período se da un doble fenómeno que tendrá una gran influencia en el desarrollo posterior de este tipo de educación. Por un lado, la Revolución Industrial conlleva una progresiva destrucción de la vida comunitaria tradicional y empuja a establecer canales educativos alternativos a los modos tradicionales de enculturación (Tiana, 1991, p. 8). Por otro lado, están los cambios político-sociales que genera la desaparición del Antiguo Régimen y de la sociedad estamental, que se ven sustituidas por regímenes parlamentarios y una sociedad de clases, donde la burguesía tiene un rol relevante:

Entre los cambios políticos e ideológicos que dicha transformación implicó, pueden señalarse la apertura (tímida, pero ya real) de procesos de movilidad social y el progresivo desuso de la fuerza y la represión como único mecanismo de control en las nuevas sociedades (Tiana, 1991, p. 8).

Desde este cambio cualitativo de las relaciones sociales puede entenderse por qué la educación de adultos no se restringió al empleo ni a la alfabetización y transmisión de lo que los ingleses llamaban las tres $\mathrm{R}$ (reeding, writing and arithmetic). Pretendiendo ir más allá de ella, a través de su propósito civilizador, la educación de adultos sirvió, pues, de instrumento para el control social, una manera civilizada de controlar al pueblo, ya que en las sociedades en vías de industrialización se tendía a asociar la educación de los adultos con el mantenimiento del orden social:

La revolución industrial había transformado profundamente los modos de vida tradicionales de las sociedades semirrurales. Las nuevas concentraciones de trabajadores en los suburbios industriales constituían un peligroso factor de desequilibrio, una amenaza potencial. La instrucción debía realizar una labor preventiva para evitar el conflicto social. Por esos motivos, las escuelas de adultos incluyeron generalmente entre sus objetivos la formación moral (Tiana, 1991, p. 15).

Si aterrizamos esta situación en el contexto nacional, a decir de Salazar et. al. (1999), la violencia popular fue una realidad en el período de transición hacia el siglo XX producto de la explotación de la clase obrera, y se la miró como una verdadera amenaza al orden establecido. Según estos historiadores, la necesidad de minimizar el conflicto social ha obedecido a la tensión entre orden y desorden y, más concretamente, tiene que ver con la necesidad de frenar al pueblo para gobernar desde arriba y sin él. Por esta razón, como parte del proyecto modernizador e ilustrado se emprendieron una serie de esfuerzos 
para contener ese malestar social y la barbarie del pueblo no ilustrado a través de la educación:

El obrerismo ilustrado, como lo ha denominado Eduardo Devés, aspiraba a la constitución de una clase trabajadora austera, disciplinada, laboriosa, respetuosa de la moral y de las sanas costumbres, conectada con las novedades científicas y técnicas del siglo. Su programa emancipador se propuso erradicar las conductas bárbaras dentro del bajo pueblo, de ahí su énfasis en la educación (Pinto, Candina \& Lira, 1999, pp. 115-116).

En este sentido, la educación de adultos ha estado en correspondencia con una cierta inducción moral del pobre, a quien se le ha querido encauzar por las buenas costumbres definidas desde la élite política y económica para evitar el peligro del caos (Salazar et. al., 1999), intentando corregir su forma de ser. Por esta razón dirá Simmel (1939) que lo que hace al pobre no es su carencia de recursos, sino la reacción que provoca en la sociedad de la cual es parte.

\section{BUSCANDO LA AUTONOMÍA}

En respuesta a este disciplinamiento de los pobres, las expresiones de resistencias dan cuenta hoy y en el pasado de las tensiones sociales que se generan para lograr el pleno desarrollo humano. En este contexto, los sujetos populares han buscado formas de equilibrar en su favor el exceso de poder de las clases dominantes y el silencio respecto de sus necesidades. “"El afán de autonomía puede interpretarse también como una forma que los sujetos populares utilizan para "descolgarse" de la modernidad, buscando alternativas de desarrollo que privilegien la autogestión”” (Pinto et. al., 1999, p. 133).

Precisamente, esta investigación aborda las condiciones en que emerge y se desarrolla un Proyecto Educativo autogestionado para la nivelación de estudios de personas adultas en Villa Valle Verde, población que nace en mayo de 1992, como consecuencia de la solución habitacional que se brindó a personas provenientes de comunas de la zona norte de Santiago. La investigación se basa en la experiencia educativa realizada en el curso del año 2014, con el propósito de rescatar el sentido que dan a la educación las personas participantes de esta iniciativa; para ello se exploran los escenarios que los actores construyen en torno a ella y los significados aducidos a su participación. También se develan significados que otorgan los sujetos al proceso educativo que desarrollan en un contexto barrial, en dialéctica con sus representaciones sociales respecto del sistema educativo. 
Al recoger esta iniciativa educativa donde sus actores asumen la responsabilidad de enfrentar con solidaridad y participación los problemas educativos de la población, enfrentando las dificultades propias que implica un proyecto autónomo en cualquier ámbito, quiero resaltar que la relevancia teórica y sobre todo práctica de este estudio, radica en el aprendizaje social que nos puede brindar, como ejemplo concreto y viable de un fortalecimiento comunitario desde la educación como problema social. Me sitúo, entonces, en una concepción amplia del concepto de educación, una manera participativa y democrática de entender este proceso, como ya lo anticipó no sólo Freire, sino también los pedagogos de la Escuela Nueva hace ya más de un siglo. Este reconocimiento me permite también ampliar el campo de la acción pedagógica, no restringiéndolo exclusivamente a las instituciones educativas, sino que es un ejercicio democrático legitimar también otras iniciativas educativas que emergen desde la ciudadanía, como respuesta a los desafíos históricos que impone la estructura social.

\section{SOBRE EL MÉTODO}

De acuerdo a la naturaleza de este problema, y como el objeto de este estudio consistía en conocer el sentido que tiene la educación para estos sujetos rescatando su contexto, me adscribí al paradigma cualitativo de investigación social. Junto con esto, reconociendo las condiciones específicas de la acción emprendida por este grupo de personas para resolver su necesidad de nivelación educacional, la investigación adoptó la forma de un Estudio de Caso.

Sin interés de reducir el problema a experiencias individuales, construí el objeto de investigación en base a lo que Cottet (2006) denomina modalidad de reconocimiento, de modo de indagar en la unidad sujeto (comunidad)/saber (del contexto), rescatando la experiencia de cada sujeto pero en tanto miembro del proyecto. Lo decisivo era resaltar la red de saber común que le daba sentido a la acción de los sujetos, las relaciones entre ellos y ellas en sus distintos roles y frente a una estructura mayor, objetivando el hecho social como contexto en el que se inscriben estas subjetividades.

Por otro lado, pensando en el rendimiento específico de las herramientas y procedimientos de recolección de datos y con el propósito de obtener datos que proporcionaran una significación de la experiencia de los sujetos, utilicé dos técnicas de recolección: la entrevista en profundidad y el grupo focal. La primera técnica fue aplicada a los educadores del proyecto y a una 
estudiante que realizaba un trabajo de memoria local de la población. Esta técnica "'pretende, a través de la recogida de un conjunto de saberes privados, la construcción del sentido social de la conducta individual o del grupo de referencia de este individuo"' (Alonso, 1995, p. 228). La segunda técnica fue aplicada con el propósito de reconstruir los esquemas de actuación de los estudiantes participantes del Proyecto, desde una doble lógica: simbólico grupal y práctico-individual, pues a través de los grupos focales “'accedemos a la dimensión 'práctica' de los mundos sociales, que se sostienen en los consensos 'cognitivos' respecto de lo 'real"' (Canales, 2006, p. 268). Apliqué esta técnica sólo a las y los estudiantes, sin integrar a los profesores, debido a que si bien las relaciones del grupo de vecinos podría calificarlas de horizontales en este espacio formativo, los educadores cuentan con un reconocimiento dentro del grupo y en la población, que creí podía influir, en algún grado, en los comentarios o en la forma de pensar de las y los estudiantes; por lo que preferí evitar cualquier tipo de condicionamiento de las intervenciones, por mínimo que fuera.

En cuanto a la selección de los sujetos, debido a que esta investigación se aleja de los métodos estadísticos, aquí no se aplica el criterio de representatividad. Como este estudio se centró en la acción de un conjunto social poco extenso, el objetivo fue abarcar una variedad amplia de perspectivas, logrando entrevistar a todos los educadores y aunque no fue así con las y los estudiantes, hubo instancias de participación con alta convocatoria, a la que asistieron hombres y mujeres que cursaban distintos grados y con distintas trayectorias educativas. Esta aspiración a una participación amplia, obedecía no a un criterio cuantitativo, sino a la necesidad de garantizar la presencia de una variedad de perspectivas de los actores, pues “"mientras más heterogéneo es el grupo, más variación de estructuras de significación pueden integrarse, de modo que el sentido se hace más complejo y denso"” (Canales, 2006, p. 283).

El análisis del problema educativo, sobre la educación de personas adultas en Villa Valle Verde, fue realizado desde el enfoque hermenéutico. La interpretación que se propone en torno a este problema, fue el resultado de un proceso de reconstrucción de un escenario a partir del lenguaje y los discursos de los sujetos participantes del proyecto educativo, con intención de reflexionar sobre su proceso y problemáticas educativas. En cuanto al método de análisis de los datos recogidos en el curso de esta investigación, utilicé la Teoría Fundamentada. En concordancia con este método y el enfoque explicitado, el propósito fue construir una historia analítica a partir de los datos, que permitiera situar el problema educativo dentro de un todo holístico, no esquemático. Con la convicción de que estamos frente a un proceso social 
vivo y no una cosa, espero reflejar el dinamismo y la riqueza cultural e histórica de la situación que enfrentan los pobladores que participan de este proyecto educativo en su barrio.

Como parte final de la codificación selectiva, realicé la validación del esquema teórico construido con los sujetos informantes, con objeto de disminuir los sesgos, pues “"una teoría fundamentada en los datos debe ser reconocible para los participantes, y aunque no encaje con cada detalle de sus casos, los conceptos más amplios sí deben poderse aplicar"” (Strauss \& Corbin, 2002, p. 177). Desde la Teoría Fundamentada, la validación no se entiende en un sentido cuantitativo, sino que, partiendo de la premisa de que la integración de categorías ““'representa una expresión abstracta de los datos brutos, [...] es importante determinar qué tan bien encaja la abstracción con los datos y si se omitió algo sobresaliente en el esquema teórico”” (Strauss \& Corbin, 2002, p. 175).

\section{ANÁLISIS DE LOS RESULTADOS}

\section{De la necesidad a la organización: un escenario a nuestro problema.}

La historia de Villa Valle Verde, desde sus inicios, es la historia de una población que se construye con esfuerzo y solidaridad. En sintonía con los relatos sistematizados en Desde lo alto, Valle Verde. Nuestra historia (s.f.), esta cualidad del contexto, emerge en el discurso de los actores, quienes aluden espontáneamente, como parte de su identidad, a su percepción del entorno barrial y su transformación a lo largo del tiempo. En el discurso de algunos sujetos se reiteran las menciones a un pasado adverso, en el que hubo que luchar y trabajar para mejorar las condiciones de vida y el entorno mismo de modo de hacerlo habitable.

Los habitantes de la Villa como "productores de espacio urbano, [fueron] pobladores en toda la esencia del concepto. En ese espacio iniciaron una 'nueva vida' y forjaron identidades colectivas que se reconocieron en el trabajo de tantas manos, sembradoras de nuevos sueños" (Pinto et. al. 1999, p. 128). La potencia de esta experiencia, asoma, constantemente en los relatos de los sujetos, por eso resulta interesante a este respecto, que en la primera entrevista realizada a una de las educadoras del Proyecto, para contarnos cómo fue que llegó a ser reconocida como profesora dentro de la población, ella evoque, precisamente, el proceso de cómo se constituyó la Villa: 
...Cuando nosotros llegamos acá era todo un peladero, habían puras chacras, parcelas y nos entregaron unos sitios y ahí ese año 92 nos empezamos a organizar con lo que tenía que ver con la seguridad, no cierto, cuidar nuestras casas, los niños y siempre nos organizamos como grupo, como Villanos nos organizamos porque estábamos muy carentes de muchas cosas: no teníamos locomoción, no teníamos caminos, estaban recién colocando los empalmes, teníamos agua pero $\cdots$ eran puros caminos de tierra, ya, entonces era difícil para, en especial para las vecinas que tenían niños que iban en el colegio, porque aquí los colegios no quedan muy cerca...

[Entrevista 1, Profesora del Proyecto Educativo]

Las menciones a un era y un ahora para aludir al contexto, las considero como claves para darse cuenta de que hubo un proceso de transformación del espacio barrial -como lo denomino en la construcción categorial. Las reiteradas alusiones de los sujetos al proceso de cómo se fundó la Villa, me impulsa a pensar que esto constituye un aspecto significativo para la comunidad, en tanto ello nos habla de su propia historia como pobladores y de un reconocimiento de lo que han logrado modificar a lo largo de dicho proceso. Este contexto al que los sujetos atribuyen sentido y lugar en sus relatos, corresponde, en este análisis, a las condiciones microestructurales de este fenómeno educativo, el escenario de la vida cotidiana de los pobladores.

Las condiciones precarias en que los nuevos habitantes de la Villa recibieron sus sitios, obligaron a la comunidad a generar instancias colectivas de participación con objeto de resolver las urgencias que dichas condiciones les imponían: acceso, locomoción, educación, seguridad, entre otros. Fue la situación de precariedad la que posibilitó la construcción de lazos de colaboración para resolver problemas que afectaban a la población. De modo que, a partir de aquí, se visualizan las primeras manifestaciones de trabajo y organización comunitarios:

Veníamos de Comités de Conchalí entonces ya algunos nos conocíamos [...]. Nos organizamos ese primer invierno, una vez que ya pasaron las lluvias salimos a protestar porque ya no nos quedó otra, protestamos en Lo Errázuriz, cerramos la calle, necesitábamos locomoción y pavimentación.

[Entrevista 1, Profesora del Proyecto Educativo]

Algo interesante en la forma como los pobladores narran el proceso de transformación del espacio es cómo surge la categoría educación, la cual 
aparece remarcada en varias oportunidades como una demanda sentida por la comunidad. Esta necesidad, en primera instancia, giraba en torno a la lejanía de los establecimientos educativos y la dificultad para llegar a ellos, considerando que no había transporte público que entrara a la población, además algunos jóvenes seguían asistiendo a las escuelas de sus antiguas residencias, igualmente lejanas y de difícil acceso. En el transcurso de este proceso, una vez asentados los pobladores, fueron reconociendo otras necesidades, por ejemplo, el gran número de personas que no había finalizado la Enseñanza Media, altos grados de deserción escolar y la existencia, incluso, de personas que no sabían leer ni escribir:

Nos dábamos cuenta que muchas de las mamitas, de las vecinas que habían acá no habían terminado su enseñanza, no habían terminado de estudiar, porque eran mamás muy jóvenes, ya, porque habían tenido que salir al campo laboral. Y estaba así como en la mente el que se pudiese tomar los estudios, pero en ese tiempo no fue posible porque no nos dieron mayor respuesta en el Municipio, no, no nos dijeron nada... $y$ quedó solamente ahí.

[Entrevista 1, Profesora del Proyecto Educativo.]

\section{Demandas educativas no atendidas y promesas no cumplidas: la emergencia a contracorriente de un proyecto educativo para personas adultas.}

Ese conjunto de necesidades educativas visibilizadas por las y los pobladores no fue atendido en esencia, pues el Municipio respondió ofreciendo talleres laborales, quedando es suspenso la solución de aquél. Fue recién con la intervención del Programa Quiero Mi Barrio ${ }^{1}$ que una de sus profesionales establece los vínculos con la Campaña Contigo Aprendo para canalizar esa necesidad local, comenzando a gestarse el primer intento de dar forma al interés de los pobladores por implementar un proyecto educativo en el sector.

Durante este proceso, ocurrió un acontecimiento significativo, que nos permite confirmar la relevancia de tales demandas y el interés de los pobladores de acceder a una oportunidad al respecto, pues, junto con implementar el Programa Contigo Aprendo, los profesionales del PQMB hicieron las gestiones con Chile Califica para que una Entidad Externa prestara el servicio educativo, logrando inscribir alrededor de 80 personas adultas para nivelar estudios de $2^{\circ}$ y $3^{\circ}$ Ciclo Básico y de 1 er. y $2^{\circ}$ Ciclo de Enseñanza Media. Sin embargo, las conclusiones finales de la intervención de esa Entidad fueron negativas para la comunidad, ya que generó un quiebre en las relaciones de confianza, debido a la negligencia de la entidad ejecutora en el proceso de inscripción: 
... Ese año [2008] vinieron de Chile Califica y teníamos alrededor de 80 alumnos en enseñanza media, $2 \times 1$. Iba todo súper bien, se asistía a clases, nosotros trabajamos paralelamente a eso con alfabetización de $1^{\circ}$ a $4^{\circ}$ Básico. Resulta que tuvimos una mala experiencia porque esta entidad se fue, los chiquillos fueron a dar sus pruebas, no estaban inscritos, nos habían perdido la documentación, la asistente social había... -a mí me consta-, porque habíamos hecho todo el papeleo y estaba todo listo, todo archivado, pero el problema es que esta entidad no presentó esta documentación al Ministerio, presentó algunas, entonces cuando los chiquillos fueron a dar los exámenes no estaban inscritos. Así que algunos de esos 80, unos 20 dieron exámenes no más y fue súper... fue muy perjudicial para la Villa porque después al año siguiente quisimos conquistar a la gente y ya no quería, no quiso participar. Todo lo que habíamos avanzao' se retrocedió.

[Entrevista 1, Profesora del Proyecto Educativo]

Más adelante, cuando se cerró el Programa Contigo Aprendo a fines del 2011, durante el gobierno de Sebastián Piñera, apareció una Universidad como Entidad Ejecutora interesada en prestar el servicio educativo a la población, y si bien continuaba vigente el problema educativo, para ese momento la confianza de los vecinos ya estaba debilitada:

La gente ya no nos creía, entonces cuando el 2012 empezamos el convenio con la Universidad [...] que estaba interesada en que los vecinos sacaran dos años en uno, pero ya no era solamente alfabetización sino que ya era $5^{\circ}$ y $6^{\circ}$, y $7^{\circ}$ y $8^{\circ}$, tuvimos que empezar a encantar a la gente, a los vecinos, motivarlos y que fuera creíble porque honestamente no creían, después de todo lo que había sucedido; hasta que conseguimos tener... ahí tuvimos 2 cursos, $7^{\circ}$ y $8^{\circ}$ y $5^{\circ}$ y $6^{\circ}$, y los que estaban de $1^{\circ}$ a $4^{\circ}$ también, los 3 niveles.

[Entrevista 1, Profesora del Proyecto Educativo]

El interés de esa universidad de prestar el servicio educativo duró hasta fines del 2013, no continuando el año siguiente debido a que, según relata la pobladora a cargo de mediar la intervención, ya no le convenía a esa institución prestar el servicio en razón del número de estudiantes inscritos. Así, ante la ausencia de algún tipo de institución que facilitara los recursos para realizar la actividad educativa, comienzan entonces a aparecer las propuestas de acción de algunos vecinos con mayor liderazgo en la población. La educadora que encabeza el proyecto investigado, comenta que diseñó, en un principio, con 
una vecina amiga, un proyecto para presentarlo al Municipio, obteniendo nuevamente otra negativa:

Ha sido bien... nosotros a comienzo de año [2014] estábamos bien contentos porque nos iban a contratar, teníamos un proyecto súper bueno y lo presentamos [en la Municipalidad]... taba todo bien y en marzo nos dijeron que no, porque los dineros... había cambio de gobierno y el dinero no taba presupuestado y dijimos "no hay dinero", entonces nosotras con la Carolina nos dijimos "pero no hay dinero, pero no podemos dejar a los chiquillos tiraos" y dijimos "no... vamos a seguir no más, de alguna u otra forma tenemos que hacer que ellos terminen la educación.

[Entrevista 1, Profesora del Proyecto Educativo]

Las estrategias de acción que algunas personas de la comunidad emplearon para resolver la demanda educativa corresponden a la acción/interacción ${ }^{2}$ que investigué en este estudio: la emergencia del Proyecto Educativo como una de las categorías centrales. Lo primero que llama la atención al respecto, son las expresiones en relación a las condiciones materiales de esta iniciativa, relativas a la situación de precariedad, pues la educadora nos cuenta que:

...este año no tenemos recursos, pero de una forma buscamos los recursos ya... por ejemplo, nos dieron útiles, fuimos al Ministerio a buscar libros, siempre andamos cachureando con la Carolina en la feria un lugar donde hayan libros, cosas que nos sirvan para los estudiantes lo tomamos. Vamos a la biblioteca, traímos mapas de allá, nos conseguimos cosas... igual nos faltan muchas cosas, nos falta un data, una fotocopiadora, tenemos que andar pidiendo, no cierto, juntar en un tarrito, pero sí hace falta apoyo en lo económico, porque se podrían lograr muchas más cosas.

[Entrevista 1, Profesora del Proyecto Educativo]

En esta misma línea, una de las propiedades que se observan en torno a las condiciones materiales del proyecto es una suerte de desinterés por parte del Gobierno local respecto al trabajo que se está realizando en la Sede Vecinal de Villa Valle Verde con las y los estudiantes adultos. El profesor de matemáticas nos señala a modo de crítica lo siguiente:

Entonces yo creo que en ese apoyo de la Municipalidad debería ser... igual estar más pendiente de lo que está pasando y quizá por eso está fallando, porque quizá no están pendientes de esto, o saben que pasa, pero bien, "que pase no má", y si está funcionando bien solo, "que funcione bien", 
entonces quizá hay un desinterés de parte de ellos, si puede haber más interés, más apoyo, yo creo habría más gente que vendría.

[Entrevista 3, Profesor del Proyecto Educativo]

Este desinterés y falta de apoyo, según perciben los participantes del proyecto respecto de su labor, cobra sentido cuando destacan el potencial social de su iniciativa, manifestando sus deseos de que otras personas también tengan la oportunidad de acceder a la educación o, en su propia expresión, que la educación llegue a ellos:

La idea de nosotros, este proyecto ambicioso, es llevar la educación no sólo acá en Maipú, sino que llevar a todos aquellos lugares, sector que son vulnerables, nosotros llevar la educación a esos lados, con un dinero, un apoyo económico detrás donde podamos tener data, podamos tener computadores $y$ donde los vecinos de varias comunas que son de sectores vulnerables, que en Santiago tenemos muchos... poder dar acceso a la educación.

[Entrevista 1, Profesora del Proyecto Educativo]

\section{Los sujetos invisibles de la educación chilena conversan sobre educación: situación y exigencias críticas.}

"Si ven a los estudiantes como un cacho, yo creo que a nosotros nos deben ver mucho menos". [Grupo Focal 2, Estudiante adulta de Enseñanza Media.]

No puedo dejar de recordar la risa que liberó en el grupo esta potente frase. La dijo una mujer que después de veinte años vuelve a estudiar. La claridad y la convicción con que hablaron las y los estudiantes que participaron en estos encuentros sobre su propia experiencia, sobre lo que implicaba para ellos y ellas, en su historia, volver a estudiar, marcan los relatos con el tinte de verdaderos testimonios de vida:

Entré a estudiar por la necesidad. Porque de repente andaba molestando porque no sé leer muy bien, molestaba de repente porque igual me ponen mala cara cuando dice “'me podí leer esto?”, o si no te quean mirando como “ ¿cómo no vai a saber?”... por eso... Intenté harto tiempo, pero los horarios de trabajo, nunca pude coincidir.

[Grupo Focal 1, Estudiante adulto de Enseñanza Básica.] 
Yo era drogadicto, yo trabajaba en Lo Valledor [...] yo llegué a los 20 años a trabajar a Lo Valledor, yo estudié hasta el año 67... 69, de ahí nunca más un libro, y hace como cuatro o seis años que estoy estudiando cuando entré a trabajar a la Muni, y gracias a los estudios salí de la droga, porque me preocupé de estar estudiando y meter materia, meter materia, se me olvidó el trago, se me olvidó el cigarro, se me olvidó la droga...

[Grupo Focal 2, Estudiante adulto de Enseñanza Básica.]

El hecho de volver a estudiar, hace pensar en qué pasa en ese período intermedio entre el abandono de los estudios y la reincorporación a un proceso educativo, en definitiva, por qué dejaron de estudiar. A su vez, todas y todos los participantes hacen hincapié en el tiempo transcurrido, el cual pareciera explicar, al menos en parte, su falta de hábitos para los estudios, o la necesidad de una modalidad de estudios más ajustada a su realidad:

Yo dejé de estudiar a los 15 años... quedé embarazada, terminé el octavo, y dejé de estudiar, me puse a trabajar para mantener a mi hija, y ahí quedé... y estaba siempre con el "quiero ir a estudiar", pero siempre me lo trancaban igual, mi marido: "qué si ya a esta altura del partío pa' qué vai a estudiar", y todo eso, hasta que la Johana me habló del programa que hacen acá para terminar los estudios, [...] hasta que dije ya, me voy a inscribir, voy a estudiar. Y aquí estoy po', toy feliz, porque yo estoy segura que voy a terminar, voy a terminar mi cuarto medio, aunque too me digan que no, que "vai a puro lesiar", que "dejai a la cabra chica botá", yo voy a terminar.

[Grupo Focal 2, Estudiante adulta de Enseñanza Media.]

Considerando estas experiencias, adquiere mayor sentido la exigencia de una estudiante al reivindicar su calidad de personas, junto con la necesidad de conocer y respetar su situación como adultos y adultas, como personas que ya tienen una estructura de vida. Al respecto, una de las profesoras destaca también entre las características psicosociales de las y los estudiantes su condición de trabajadores y trabajadoras como contexto que se debe considerar:

Me gustaría si pudiéramos mandar un mensaje al Ministerio de Educación, decirle al Ministerio que no somos sólo un número, que también somos personas y somos parte de la sociedad, y que, como sociedad, nosotros también tenemos derechos. Y como somos gente adulta que ya llevamos una etapa de la vida recorrida, se nos hace más difícil estudiar, entonces 
necesitamos un apoyo especial para nosotros, personas idóneas para que nos enseñen, porque nosotros somos la materia y estamos dispuestos...

[Grupo focal 2, Estudiante adulta de Enseñanza Media.]

... La gran mayoría, los varones, trabajan en fábricas, son operarios. Otros trabajan en las áreas verdes, en jardín, en plazas, y hay otro porcentaje que son dueñas de casa. Los varones todos trabajan en forma apatronada y hay ahí también, hay varios que son independientes, que son ferianos [...], que trabajan en el comercio. [...] Las mujeres algunas trabajan en... son operarias, otras trabajan haciendo aseo en casas y otras son dueñas de casa.

[Entrevista 1, Profesora del Proyecto Educativo.]

Además de exigir un mayor reconocimiento por parte de las autoridades gubernamentales, en el sentido de considerarlos como personas con historia y necesidades específicas, los pobladores hacen ver el desinterés por su proceso educativo y sus aprendizajes logrados, dando cuenta de cómo se representan el funcionamiento del sistema educativo y cuáles son, a juicio de ellos, sus intereses reales:

Cuando hacen las estadísticas el Gobierno, de la alfabetización, toas las personas que han logrado sacar $4^{\circ}$ medio a ellos les favorece el que el país no tenga tanta... tantas personas analfabetas. ¿Pero realmente están interesao en uno?, ¿en saber si uno realmente aprendió, si uno realmente lo que pudo lograr al rendir un examen le fue bien, qué está haciendo, qué pasa después con nosotros? ¿Estará realmente el Gobierno preocupado de eso?

[Grupo focal 2, Estudiante adulta de Enseñanza Media.]

En congruencia con estos razonamientos, los estudiantes también resaltan las contradicciones que dicen ver en el sistema educativo y también cómo creen que son vistos por éste. En una dura reflexión, denuncian que los apoyos a su proceso educativo no superan lo verbal, ya que no hay aportes concretos al proyecto, catalogándose como un número a ojos del sistema o sencillamente como sujetos invisibles, tal como la cita inicial de este apartado:

Como dicen somos un número no más, porque a ellos les conviene... ellos dicen pucha "antes teníamos el 50\% de analfabetismo y... pero ahora tenemos el 20\% no más”, pero las personas que aprendieron no saben si realmente aprendieron o no...

[Grupo focal 2, Estudiante adulta de Enseñanza Media.] 
Algunas estudiantes amplían esta mirada crítica, destacando nuevos aspectos que, al parecer, forman parte del mismo problema. El desinterés por las personas y sus procesos educativos, así como la falta de oportunidades, son atributos del sistema que pueden palpar en sus vidas y en sus propios hogares:

No hay una exploración de los pobladores. Yo misma ahora estoy haciendo [...] una recopilación del Sector 1 de Los Presidentes que es la gente pionera. Yo he entrevistao a varias personas y a la manera de pobladora, no de un alcalde... porque la otra vez se nos entregó así... a nosotros se nos entregó un libro de Cerrillos, pero salía casi puro del Aeropuerto y fue por un puro testimonio de una vecina pobladora que "ah... nosotros cuando vivimos en Las Lomas era así, era asá, íbamos a buscar sapolio a la línea del tren" y yo también viví eso [...]. Pasamos por muchas cosas. Entonces toas esas cosas yo las estoy escribiendo.

[Grupo focal 1, Estudiante adulta de Enseñanza Básica.]

En este contexto, quizás se puede comprender mejor los significados que emergen en torno a la educación, asociados a la idea llegar a ser alguien dentro de la estructura social, de ser reconocidos o visibilizados por el sistema y la sociedad, que se perfila como uno de los sentidos más legitimados por los estudiantes de esta comunidad:

Por eso es esencial la educación... Porque si no tienes educación no eres nadie, no eres nadie sin educación. Como dice el Víctor antes era nadie, pero ahora que está terminando la educación es "don" Víctor. Por eso la educación es importante.

[Grupo focal 2, Estudiante adulta de Enseñanza Media.]

Esta idea de que sin educación no eres nadie puede entenderse en un contexto de segregación, si se tiene en cuenta el peso social que implica la certificación y las limitaciones que conlleva no contar con ella, "al lograr la perpetuación de la estructura de la distribución permanente que, aunque tenga todas las apariencias de la igualdad, está marcada por un sesgo sistemático en favor de los que poseen un capital cultural heredado" (Bourdieu, 2011, p. 111). Por eso, una de las profesoras del proyecto afirma sobre este sentido asignado a la educación que:

[P]arece desoladora, muchas veces yo digo, pucha estos estatus que te da la sociedad, estos estereotipos donde te dicen, si tú tienes cuarto medio o tení un título profesional o trabajas detrás de un mostrador, tienes poder y eres alguien. Pero si tú estás en tu casa, como jefe de hogar o 
eres un obrero, eres una sombra más, eres nadie para el resto del mundo. Es fuerte el saber que ellos tienen esa visión de ellos mismos y que se sienten de esa forma, porque insisto, la sociedad los ha hecho sentir así.

[Entrevista 4, Profesora del Proyecto Educativo.]

Pronto se observan, a partir de estas nociones, la educación como condición interpuesta por el sistema para acceder a un empleo, o para presionar a las personas para que completen sus estudios, conceptualizándola como exigencia y obligación. Como uno de los extremos de las variaciones de significados, aparece la idea de que si no fuera así, no habría razón de estudiar:

[Si no fuese requisito] no sería tan importante, si no fuese así la historia, ¿pa’ qué va a estudiar uno?

[Grupo focal 3, Estudiante adulto de Enseñanza Básica.]

[La educación] es algo esencial, algo que nos facilita la vida, porque para un trabajo nos exigen cuarto medio, entonces es algo esencial para las personas...

[Grupo focal 2, Estudiante adulta de Enseñanza Media.]

Sin embargo, vuelven a aparecer las contradicciones del sistema, pues los estudiantes, al mismo tiempo que reconocen esta exigencia, hacen ver también que al sistema no le interesa que las personas se desarrollen educativamente, porque, según lo que señalan, atentaría contra los intereses de las empresas. Por otra parte, una educadora reafirma su sospecha respecto de los intereses reales de instruir al pueblo, ya que un pueblo instruido es consciente de sus necesidades y exige desde ese poder lo que requiere:

A ellos [los patrones] no les conviene que te superí [...] porque en las áreas verdes a ellos lo único que les interesa es que les cortí el pasto, les arreglí los jardines, nada más po', si a ellos les interesa el trabajo, a ellos les pagan por eso.

[Grupo focal 3, Estudiante adulto de Enseñanza Básica.]

¿Para qué yo quiero un pueblo instruido?, ¿para qué me diga y me plantee las necesidades que tiene, con conocimiento de causa, decir, "sabes qué esto y esto es lo que nosotros necesitamos"?

[Entrevista 4, Profesora del Proyecto Educativo.] 


\section{Vecinos-compañeros y construcción de comunidad: una nueva categoría para entender el proceso educativo.}

La crítica que sostienen los sujetos que participan en este proyecto, al reclamar mayor interés y apoyo a su proceso educativo, resuena desde un lugar: el vecino. Por ende, la manera en que los actores comprenden su propia situación devela sus problemas educativos como pobladores. En efecto, si recordamos el principio de este análisis sobre el contexto, entendemos cómo las prácticas vinculares que constituyen el espacio social de la Villa, imprimen su sello en la problemática educativa. Así, el fenómeno central que aparece en este estudio, como patrón de acción de esta comunidad, es la construcción de redes de apoyo entre los vecinos para resolver sus problemas sociales. Este patrón que se reitera en la comunidad, se observa desde la constitución de la población, cuando los vecinos se organizaron para mejorar las condiciones de vida y del espacio barrial, donde el trabajo comunitario fue la acción estratégica de la comunidad para sortear las dificultades y las necesidades no resueltas por la institucionalidad, las cuales, inicialmente, estaban vinculadas al problema habitacional y que, más adelante, fueron sustituidas por nuevas necesidades, frente a las cuales los vecinos adoptaron las mismas estrategias:

Ese espíritu de convivencia se refleja en situaciones tales como el cuidado mutuo de las viviendas o el apoyo que se organizaba -por pasajes o por cuadras- cuando una familia se encontraba pasando por dificultades económicas, enfermedades o cualquier otro momento complicado. Ya en esos primeros tiempos ese espíritu de comunidad se inculcó entre los vecinos, especialmente entre los de más edad, como una herramienta útil para mejorar sus condiciones de vida y mejorar su entorno (Desde lo alto Valle Verde, nuestra historia [s.f.], p. 22-23).

Reforzando lo anterior, en este documento de reconstrucción histórica de la Villa se rescata que esta experiencia ya se encontraba previamente a la llegada de los nuevos pobladores a Valle Verde, producto de la organización en los Comités Habitacionales, que debieron organizar a un gran número de personas para el logro de la casa propia. Llamaremos a este patrón de acción recurrente entre los vecinos prácticas comunitarias. Téngase en cuenta que por patrones se entiende ciertos fenómenos "que representen lo que las personas dicen o hacen, solas o en compañía, en respuesta a los problemas y situaciones en los que se encuentran" (Strauss \& Corbin, 2002, p. 142). Tales fenómenos nos dicen qué sucede aquí, cuál es el asunto medular en este problema. 
Al resaltar estas prácticas comunitarias como fenómeno que se reitera en esta comunidad, no pretendo dar por sentado lo comunitario a modo de un a priori, como si fuese posible transponerlo a toda dinámica barrial y a todo vínculo entre pobladores. No es mi interés hacer de lo comunitario un arquetipo teórico que nos impida ver la riqueza del encuentro entre los vecinos participantes en este Proyecto Educativo; más bien, interesa destacar cuáles son los escenarios que los pobladores instalan en torno a este Proyecto:

Hay mucha gente que no sabe leer ni escribir, porque no han tenido el agrado de tampoco de vivir este momento que nosotros estamos haciendo...

[Grupo focal 2, Estudiante adulta de Enseñanza Media.]

La idea a través de este proyecto de que ellos logren sacar la enseñanza básica, la media y después un convenio, como yo te decía, con estudios técnicos o superiores, y la idea es que ellos mismos después que terminen puedan entregar aunque sea un año a la comunidad, que ellos puedan devolver lo que a ellos se les dio, porque así se enriquecen y le va a servir a los otros alumnos, porque ellos van a ver la experiencia [...], porque creo que nadie aprende más cuando tú das testimonio de lo que aprendiste, es la mejor enseñanza...

[Entrevista 1, Profesora del Proyecto Educativo.]

Pues bien, ¿cómo surge lo comunitario? ¿Qué hizo que este proyecto llegara a ser comunitario, más allá de las intenciones de algunos individuos? Partiendo por el principio, a saber, cómo se conforma este Proyecto Educativo, los datos muestran que éste se constituye como un espacio que les permite a las personas adultas terminar sus estudios. Con esto se pretende iluminar que los estudiantes se integraron al proyecto por motivos individuales, movilizados por su interés de terminar su escolaridad interrumpida por diversas razones: por falta de colaboración o conocimiento en la familia, por la llegada de un hijo, entre otros, tal como señalan en los testimonios sobre su experiencia de volver a estudiar. ¿Pero qué pasa cuando las expectativas individuales se encuentran con un conjunto de prácticas que son colectivas? Es decir, estas prácticas no habrían sido previstas o buscadas per se, en el sentido de que las y los adultos no se hicieron parte del proyecto movidos por esta finalidad, menos aún si consideramos que coexistimos en una sociedad individualista. $\mathrm{Si}$, evidentemente, ninguna de esas necesidades individuales constituye un Proyecto Comunitario, entonces ¿cómo se desarrolla el espacio educativo de manera que pueda dar lugar a prácticas comunitarias que superen los intereses individuales? ¿Qué sucedió en el proceso para que surgiera lo comunitario? 
Pues bien, al indagar en factores que han motivado a los adultos a asistir a las clases y formarse en la sede vecinal, las explicaciones llegan a la importancia del vínculo, del apoyo mutuo, condiciones que, a juicio de los sujetos, favorecen el proceso educativo:

Yo creo que los motiva el grupo que hay, lo que más los motiva es estar juntos con otros, con sus pares, porque la gran mayoría de ellos son su casa y su trabajo, no tienen mayor actividades. Uno que otro participa a lo mejor en la JJ.VV., pero en general ellos son muy eh... su casa, su trabajo, en cambio ahí echan la talla, conversan, se conocen, algunos se enamoran, entonces eso que los motiva a ellos...

[Entrevista 1, Profesora del Proyecto Educativo.]

Yo creo que para ellos es más como una familia, más que amigos en el colegio, ellos son más unidos que eso. Al ser así yo creo que ellos se apoyan mucho más, ellos aprenden mucho más, porque tienen la confianza entre ellos de poder consultarse las cosas. En cambio cuando uno está en el colegio no po', cuando está en el colegio uno ya si no aprendió “cómo le voy a preguntar a mi compañero?”. Igual hay como más desunión en el colegio que en algo así que son todas personas conocidas, todos se van a dejar...

[Entrevista 3, Profesor del Proyecto Educativo.]

Finalmente, las necesidades individuales devienen en prácticas comunitarias, esto queda cristalizado en la cualidad del vínculo que permite ser, a la vez, vecinos y compañeros de clase, tal como advierten los educadores. Y también se advierte cuando los sujetos parecen haber descubierto algo en este espacio social que no pretendían encontrar:

En grupo como que... a sacar la voz aprendemos... a sacar la voz en grupo. Porque hay cosas que uno piensa que... uno dice "lo pienso yo no más, no hay más", pero si nos juntamos en grupo y empezamos a conversar, viendo too, todos pensamos lo mismo.

[Grupo focal 2, Estudiante adulta de Enseñanza Media.]

De acuerdo a lo que se viene planteando en torno a cómo se gesta lo comunitario en este proyecto, diríamos que tanto estudiantes como educadores atribuyen un sentido relevante en el proceso a los vínculos que han ido construyendo los alumnos entre sí, y también éstos con los profesores. La idea de familia y de unión entre pares que posibilita esta propuesta educativa, me permitió configurar el concepto de vecinos-compañeros como categoría que 
nos permite evocar el arraigo y la identidad con un territorio, dentro del cual surge un lazo diferente, pero que acentúa esa unión en torno a un problema común relacionado con lo educativo. Este constructo, nos permite visualizar cómo los sujetos descubren en lo educativo una manera diferente de habitar ese espacio común, de reconocerse como partes de un territorio y como sujetos que enfrentan problemas comunes.

Situando este problema social y educativo en su contexto social más amplio, en el que se cruza la lógica neoliberal y la neo-centralista -desencadenados a partir de la dictadura militar-, los cuales han mermado el tejido social haciendo del individuo un estandarte, principio y fin de nuestras acciones, el concepto propuesto de vecinos-compañeros, como uno de los resultados principales de esta investigación, permite iluminar que los vínculos son posibles en una sociedad donde éstos han sido debilitados. La importancia de este concepto reside en su potencial social para construir una vía posible para desandar el camino de la modernización individualista:

La vecindad era un lazo social que integraba a toda la familia y todos los aspectos de la vida. Reunía en sí, por ello, a la vez, la legitimidad y el poder soberano. Históricamente, ningún otro vínculo ha comportado la socialidad en tal grado de profundidad e integralidad; ni, tan directamente, la fuente del poder. (Salazar et. al., 1999, pp. 264-265).

Ligado a este sentido de comunidad y al lazo de la vecindad, se configura también un concepto de educación bastante enriquecedor para los pobladores. La educación en su sentido comunitario, es uno de los significados emergentes en torno a la educación y el que constituye un hallazgo importante de este estudio, que refuerza el patrón que se identifica como característico de las prácticas de los vecinos de la Villa:

me gusta ver mucho cómo los vecinos aprenden, y ver que ahora ellos me dicen pucha... "puedo leer mi contrato de trabajo", "puedo saber lo que me dicen", "ya entiendo otras cosas"... se pueden defender.

[Entrevista 1, Profesora del Proyecto Educativo.]

Junto con este sentido comunitario, se rescata como una propiedad importante de esta modalidad educativa, la autonomía, que aparece como una valoración positiva del proceso. Desde el punto de vista de las y los estudiantes, se destaca que el proyecto brinda dinámicas de funcionamiento más acordes a sus tiempos y a sus responsabilidades como adultos, constituyéndose incluso, en algunos casos, como la alternativa para nivelar los estudios, destacando el 
fácil acceso y la flexibilidad horaria, a diferencia de un colegio que exige, a su entender, dedicación total. Por su parte, los educadores destacan la autonomía como una finalidad formativa y la libertad para realizar las actividades sin ningún tipo de acompañamiento en esta modalidad de examinación libre:

Aquí nosotros somos nuestros propios agentes, por horario, en responsabilidad.

[Grupo focal 2, Estudiante adulta de Enseñanza Media.]

Por qué me gustan los adultos, allí con los adultos tú puedes hacer cosas, porque trabajai' con ellos sin que nadie te esté diciendo lo que tienes que hacer, tenemos el decreto 236 [sic], no cierto, hacemos la planificación, todo en orden, pero tenemos que hacerlo solos, porque no hay ninguna entidad...

[Entrevista 1, Profesora del Proyecto Educativo.]

Yo me inscribí en el colegio en marzo, allá en Bueras de Maipú, no, Bernardo O'Higgins, que está en Segunda Transversal con 5 de Abril, pero con los turnos de noche andaba con la cabeza así media... (llevándose las manos a la cabeza) no pude, tenía que irme volando de ahí... del Colegio irme a trabajar, así que supe que había aquí exámenes libres que se dan, igual se estudiaba pero ya era mucho menos que allá, menos horas, yo má' o meno el año ochenta y... no po' ' 78... que no estudio, ahí saqué el octavo, no po', saqué el séptimo, y después adulto me compré una moto y no tenía octavo y ahí me inscribí en el Ministerio me mandaron a hacer una prueba... el 2008 ahí saqué el octavo...

[Grupo focal 2, Estudiante adulto de Enseñanza Media.]

De acuerdo con las explicaciones de las y los estudiantes, se puede inferir que la Escuela no está pensada sino para aquellos que tiene como única responsabilidad el estudiar, es decir, estaría dirigida a los niños y jóvenes, pero no para las personas adultas, quienes ya cuentan con una estructura mental definida y una trayectoria de vida al margen de la sistematicidad a que obliga la educación formal. La escuela tampoco ofrecería en la práctica algún tipo de fase propedéutica para aquellas personas que durante años, e incluso décadas, han dejado de estudiar. Tales dificultades alejarían a estas personas a buscar en esta institución una oportunidad para de una vez terminar con lo que hace tiempo ya abandonaron. De algún modo la Escuela estaría hecha para moldear a las nuevas generaciones, modalidad en la que los sujetos populares no siempre quieren entrar, resistiéndose y buscando formas y caminos que se ajusten a su 
manera de vivir la vida. Así, algunos sujetos deciden nadar contra la corriente o simplemente restarse a un proyecto que sienten ajeno.

\section{CONCLUSIONES}

Bajo la premisa de que "comprender la cultura de un pueblo supone captar su carácter normal sin reducir su particularidad” (Geertz, 2003, p. 27), cuando comencé con la indagación en torno al objetivo central, referente a los sentidos que otorgan a la educación los sujetos participantes de este Proyecto Educativo, intenté reconocer las prácticas más distintivas que constituían a la comunidad, para más adelante escudriñar en algo que pudiese destacarse como novedoso dentro de la cotidianidad de las dinámicas de los pobladores de Valle Verde. Entre esas prácticas distintivas, correspondientes a sus patrones de acción, identifiqué las relaciones de intercambio, colaboración y solidaridad. Lo difícil y trabajoso que fue para ellos y ellas poblar la Villa y empezar de la nada, los hizo valorar el apoyo y la ayuda mutua para hacer frente entre todos lo que podría haber sido más adverso aún, o incluso imposible de sobrellevar, en solitario. Por lo mismo, los sujetos asignan un valor importante a lo que nace de la dificultad, porque, a su entender, serían logros más reales que aquellos que se obtienen de manera fácil o inmediata:

Cuando uno opta a un proyecto y el proyecto tiene dificultades, es porque está dando buenos resultados, porque cuando, a lo mejor, todo está como en un vaso de leche, es porque algo pasa, es mejor la adversidad porque así yo mejoro, me pongo más metas...

[Entrevista 1, Profesora del Proyecto Educativo.]

De ahí que pueda entenderse por qué el concepto de vecinos-compañeros constituye el principal hallazgo de esta investigación y sintetiza el tema esencial. Bajo este constructo, agrupé los sentidos que expresaron los entrevistados que apuntaban a un tipo de vínculo especial que se daba entre los pobladores participantes del proyecto, el cual reforzaba, en un nuevo contexto, las prácticas comunitarias de los vecinos. En este escenario, se construyen dos tipos de significados en tensión en torno a la educación en consonancia con la situación macro y micro social:

\section{Un concepto de educación que nace desde arriba:}

En relación a la estructura social las y los participantes reconocen, por un lado, las exigencias que establece el sistema educativo para disminuir los índices 
de analfabetismo y así el país pueda competir internacionalmente; por otro, las condiciones que establecen las empresas y el mercado para optar a un trabajo decente. Desde estas condiciones macro-estructurales, los sujetos perciben la educación como una imposición del sistema, como una condición para lograr acceder a otros beneficios y para tener reconocimiento social. Sin embargo, a pesar de sentir esta imposición los sujetos critican que, paradójicamente, hay un desinterés por la educación de adultos. A decir de ellos, en la pobreza pasa lo mismo que en la educación, porque al pobre como al que no tiene certificación se lo trata mal, pues "es parecido [ser pobre] a no tener estudios, si no tienes estudio eres una persona que no vales nada, si tienes estudio te consideran más que una persona que no ha estudiado nunca" [Grupo focal 4, Estudiante adulto de Enseñanza Básica].

\section{Un concepto de educación que nace desde abajo:}

En tensión con la presión del sistema que dicen sentir los sujetos, emerge en la experiencia de educarse con los vecinos y vecinas una manera distinta de vivir el proceso educativo. Los profesores resaltan la importancia del compromiso de sacar adelante a la comunidad, más allá de que se cuente o no con recursos, y de la unión se ha ido construyendo en el camino. Los estudiantes descubren que juntos toman conciencia de que les sucede lo mismo, que en el vecino hay alguien que puede ayudarles en su aprendizaje, que ocupar los espacios comunes del barrio hace de este proceso algo más cercano, flexible y a la medida de las personas, frente a la impersonalidad y la exigencia de los Colegios, donde lo único que importaría es aprender, pero no quien aprende. Este sentido comunitario asignado a la educación, resalta la importancia que tiene para estudiantes y educadores la colaboración y compañía en el aprendizaje y la necesidad de ser reconocidos por sus pares, como el lugar donde pueden ser personas de carne y hueso.

En una época donde se instrumentalizan las relaciones y a las personas mismas, la categoría central de esta investigación muestra una posibilidad de reconstrucción de los vínculos sociales a través de un intercambio que no sigue la lógica del capital ni del individualismo moderno. "La socialidad en sentido pleno" (Salazar et. al., 1999) que recoge la categoría de vecinos-compañeros nos permite visualizar que aun cuando ha habido históricamente el interés autoritario de despojar a las bases ciudadanas de su poder, éste sigue ahí con ellas y se manifiesta en la decisión de asumir la responsabilidad de los asuntos públicos. 


\section{Proyecciones:}

Este estudio se suma a la propuesta de las y los entrevistados de que su experiencia educativa pueda replicarse en otros contextos para que la educación llegue a las personas, pero sería necesario plantearse las condiciones de una educación barrial, porque si se observa críticamente la historia de la educación popular, a pesar de lo que muchos creen, no siempre se desarrolló autónomamente (Salazar, 1996). Interesa, por tanto, que los lectores puedan reflexionar sobre cuál de las modalidades de una educación barrial comunitaria puede ser más idónea, es decir, situarnos frente a la encrucijada de la autonomía o el patrocinio: si será mejor que proyectos como estos puedan optar al financiamiento o si debiesen mantenerse al margen de esto para elaborar según su arbitrio la educación que necesitan. Cada opción tiene sus pros y sus contras.

\section{NOTAS}

1. En adelante PQMB.

2. En palabras de Strauss \& Corbin (2002: 146) "Las acciones/interacciones estratégicas son actos deliberados o ejecutados a propósito para resolver un problema, y al hacerlo moldean el fenómeno de alguna manera".

\section{REFERENCIAS BIBLIOGRÁFICAS}

Alonso, L. 1995 Sujeto y Discurso: El lugar de la entrevista abierta en las prácticas de la sociología cualitativa. En: Delgado, J. \& Gutiérrez, J. (Eds.). Métodos y técnicas cualitativas de investigación en Ciencias Sociales (p. 225-240). Madrid: Síntesis.

Bourdieu, P. 2011 Capital cultural, Escuela y Espacio Social (2Ed.). México: Siglo XXI Editores.

Canales, M. 2006 El Grupo de discusión y el Grupo Focal. En Canales, M. (Ed.), Metodologías de Investigación Social: Introducción a los oficios (pp. 265-287). SantiagoChile: LOM Ediciones. 
Cottet, P. 2006 Diseños y estrategias de investigación social. Estrategias cualitativas. En Canales, M. (Ed.), Metodologías de Investigación Social: Introducción a los oficios (pp. 185-217). Santiago-Chile: LOM.

Desde lo alto Valle Verde, nuestra historia (s.f.).

García de la

Huerta, M. 2013

Geertz, C. 2003

OECD 2015
Andrés Bello: "intelectual orgánico" de la república conservadora. En Ossandón, C. \& Ruíz, C. (Coord.). Andrés Bello, Filosofía pública y Política de la letra (pp. 147-159). Fondo de Cultura Económica.

Descripción densa: hacia una teoría interpretativa de la cultura. En Geertz, C. La interpretación de las culturas (p. 17-40). Barcelona, España: Gedisa.

Todos juntos. ¿Por qué reducir la desigualdad nos beneficia? Recuperado el 18 de octubre de 2015 desde OCDE, Sitio web: http://www.oecd.org/chile/ OECD2015-In-It-Together-Highlights-Chile.pdf

Pinto, J., Candina, El sujeto popular. En G. Salazar \& J. Pinto (Eds.), A. \& Lira, R. 1999 Historia contemporánea de Chile. Actores, identidad y movimiento (Vol. II) (pp. 93-136). Santiago, Chile: LOM.

Salazar, G. 1996 Las avenidas del espacio público y el avance de la educación ciudadana. Recuperado el 4 de septiembre de 2015 desde: http://www.archivochile.com/Ideas_ Autores/salazarvg/salazarvg0015.pdf

Salazar, G., $\quad$ Comunidad, gobierno local, participación. En: G. Mancilla, A., \& Salazar \& J. Pinto (Eds.), Historia contemporánea de Durán, C. 1999 Chile. Estado, legitimidad, ciudadanía (Vol. I) (pp. 263-311). Santiago, Chile: LOM.

Simmel, G. 1939 El pobre. Digresión sobre la negatividad de ciertas conductas colectivas. En Simmel, G. Sociología. Estudios sobre las formas de socialización. Trad. de J. Pérez Bances (p. 57-94). Buenos Aires, Argentina: Espasa Calpe. 
Strauss, A. \&

Corbin, J. 2002

Tiana, A. 1991
Bases de la investigación cualitativa. Técnicas y procedimientos para desarrollar la teoría fundamentada. Trad. Eva Zimmerman. Medellín: Editorial Universidad de Antioquía.

La Educación de Adultos en El Siglo XIX: Los Primeros pasos hacia la constitución de un nuevo ámbito educativo. En Revista de Educación N²94 (pp. 7-26). Recuperado el 4 de septiembre de 2015 de: http://www.mecd.gob.es/dctm/ revista-de-educacion/articulosre294/re29401. pdf?documentId=0901e72b813576a4

Zemelman, M. \& Jara, I. 2006
Seis Episodios de la Educación Chilena, 1920-1965, Santiago, Chile: Ediciones Facultad de Filosofía y Humanidades, Universidad de Chile. 
